

Bob Sams

Director,

ANR Communication Services

\title{
Of Mendel, wikis and open source: New models for knowledge creation
}

IN 1866, Gregor Mendel published his paper "Experiments with Plant Hybridization" and set a foundation for modern genetics and the laws of inheritance. As with many keystone achievements, the importance of his paper was not recognized at the time. Thirty-five years later, long after Mendel's death, rediscovery of his work generated rapid advances in our understanding of genetics and marked a starting point for the research that has improved plant and animal breeding, shown us the structure of DNA, and helped us elucidate the risks and benefits of biotechnology.

However, that is only part of the benefit from Mendel's work and the 140 years of review, replication and analysis that followed. It is not as well known that Mendel's experiments were also studied carefully by Richard Fisher, English statistician and evolutionary biologist. Fisher concluded that Mendel's findings were just too close to expected results - and while the accuracy of Mendel's hypothesis is not challenged today, his work is cited as an example of how smoothing data can lead to confirmation bias. Fisher's later career included work at the famed Rothamstead Experimental Station in England and as visiting faculty at Iowa State University, where he contributed greatly to modern statistical science. Mendel's work and Fisher's analysis are examples of the tradition of open inquiry and scientific dialogue that are the reason for publishing this magazine and for reporting research results openly and accessibly.

As California Agriculture marks its 60th anniversary (see page 174), the journal is working hard not only to publish new findings but also to realign production, publication and distribution methods with rapid technological advances in communications. First among these changes is the continuing growth of the Internet. The World Wide Web has become the dominant information retrieval pathway, especially in science, education and business. Two things have fueled this evolution. Digitized content has grown explosively and there is no end in sight. In a recently announced agreement, UC and Google will undertake to digitize and index selected contents of the UC library system, as well as those of other major institutions. Combined with similar initiatives by Yahoo and other search engines, this agreement shows that society has implicitly and collectively agreed that this Herculean task is both possible and desirable. It also demonstrates our confidence that the technology behind today's powerful search engines is capable of storing, indexing and retrieving that information.

Secondly, growing online communities based on "social networking" permit both direct conversations between individuals as well as specialized Web publishing through blogs, Web forums, wikis and virtual communities. Cooperation and collaboration are no longer limited by time or distance, nor are online reviews, online real-time editing or instant publishing. These developments promise to vastly reduce publication costs. The open-source software development community demonstrates that virtual teams can accomplish highly complex tasks and distribute valuable products.

These technical and behavioral changes are disruptive. In fact, Dan Greenstein, university librarian and head of the California Digital Library, has figuratively called them "subversive." New forms of popular and academic publishing will affect scholarly communications much as Web distribution has revolutionized the music industry and newspaper publishing. New kinds of copyright licenses and new definitions of intellectual property rights will be required. One significant effort to define these agreements is the Open Content Alliance. Web archives and aggregators such as UC's own eScholarship Repository and the national Web project eXtension are working to develop open models of content creation, attribution, licensing and ownership.

For California Agriculture and all ANR publications, these changes are important, difficult and exciting. Communications and information technology professionals see many tantalizing, confusing and unknown pathways to the open and broad dissemination of peer-reviewed research results. We also see a bewildering array of tools to deliver the benefits of new knowledge to society.

To take full advantage, we must do more than ensure that content exists on the Web and that it is appropriately indexed and recognized by search engines. We must also engineer online peer-review processes that are flexible enough to accommodate the whole range of information and publication methods, from refereed journals to one-page fact sheets. We must explore new forms of community or "salon" review that allow editorial or content changes to Web information in real time. We must also adapt to changing notions of intellectual property and copyright. In a letter to the editor (page 173), Lawrence Pitts, chair of the UC Academic Council Special Committee on Scholarly Communication, reminds us that all of UC shares an obligation to the common good, a value that has always been at the core of ANR's mission. At the same time, we must ensure the quality of our information, protect its identity and source, and deliver it in an effective form to the people of California. We are working to see that California Agriculture continues its 60-year tradition of doing just that.

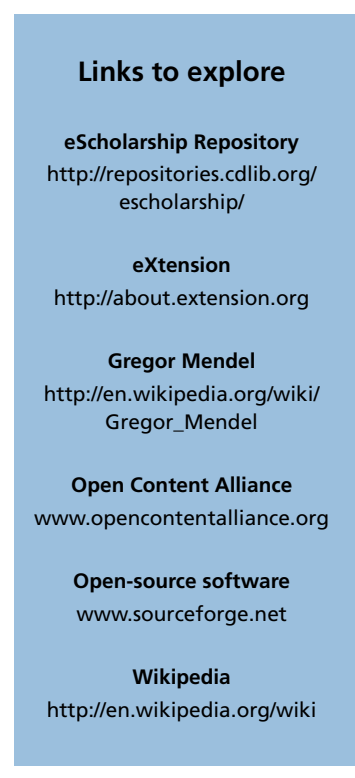

